\title{
Clobazam as Add-on Therapy in Children with Epileptic Encephalopathy
}

\author{
Rosana Carvalho Silva, Maria Augusta Montenegro, \\ Carlos A.M. Guerreiro, Marilisa M. Guerreiro
}

\begin{abstract}
Rationale: Clobazam has been used successfully in adults and children with partial epilepsy. The purpose of this study was to evaluate the safety and efficacy of clobazam as add-on therapy in children with epileptic encephalopathy. Methods: This was a retrospective study conducted at the pediatric epilepsy clinic of our university hospital. Children less than 18-years of age with epileptic encephalopathy were included in the study. Clobazam was introduced as add-on therapy, starting with $5 \mathrm{mg} / \mathrm{Kg} / \mathrm{day}$ and increased in minimally effective doses, up to the maximum tolerated dose. Data were obtained from clinical files and follow-up visits. Results: Ninety-seven patients were included in the study (39 girls), aged between 1 and 17-years-old (mean = 9.9). Twenty-six patients had Lennox-Gastaut syndrome, seven had myoclonic astatic epilepsy, nine had West syndrome and, in 57 patients, the type of epileptic encephalopathy could not be determined. Clobazam dosage ranged from 5 to $60 \mathrm{mg} /$ day (mean $=37.5 \mathrm{mg} / \mathrm{day}$ ). Forty $(41 \%)$ patients presented with adverse events, most of which were mild and transitory, and clobazam needed to be withdrawn in only 11 patients. Nine $(9.2 \%)$ patients were seizure-free after clobazam adjunctive therapy. In $11(11.3 \%)$ patients seizure improvement was $>75 \%$, in 16 $(16.5 \%)$ it was $>50 \%$, in $17(17.5 \%)$ improvement was $<50 \%$ and in $44(45.5 \%)$ there was no change in seizure frequency. Three patients were lost to follow-up. In $85 \%$ of the patients with seizure improvement, the results lasted for more than one year. Conclusion: Clobazam is safe and effective in the treatment of epileptic encephalopathies of childhood.
\end{abstract}

RÉSUMÉ: Le clobazam comme traitement d'appoint chez les enfants atteints d'encéphalopathie épileptique. Justification: Le clobazam a été utilisé avec succès chez les adultes et les enfants atteints d'épilepsie partielle. L'objectif de cette étude était d'évaluer la sécurité et l'efficacité du clobazam comme traitement d'appoint chez les enfants atteints d'épilepsie partielle. Méthodes: Il s'agit d'une étude rétrospective chez des enfants de moins de 18 ans atteints d'encéphalopathie épileptique, qui fréquentent la clinique d'épilepsie pédiatrique de notre hôpital universitaire. Le clobazam était prescrit comme traitement d'appoint avec une dose de départ de $5 \mathrm{mg} / \mathrm{Kg} / \mathrm{jour}$. La posologie était augmentée progressivement d'une dose efficace minimale jusqu'à la dose maximale tolérée. Les données ont été tirées des dossiers cliniques et des visites de suivi. Résultats: Quatre-vingt-dix-sept patients ont été inclus dans l'étude (39 filles et 58 garçons), âgés de 1 à 17 ans (moyenne de 9,9 ans). Vingt-six patients étaient porteurs du syndrome de Lennox-Gastaut, sept étaient atteints d'épilepsie astatique myoclonique, neuf du syndrome de West et le type d'encéphalopathie épileptique était indéterminé chez 57 patients. La dose de clobazam variait de 5 à $60 \mathrm{mg} /$ jour (moyenne de 37,5 mg/jour). On a observé des incidents thérapeutiques chez quarante patients (41\%) et la plupart ont été légers et transitoires. On a dû cesser l'administration du clobazam chez 11 patients seulement. Neuf patients $(9,2 \%)$ n'avaient plus de crises après l'introduction du clobazam comme traitement d'appoint. Chez 11 patients (11,3\%) l'amélioration était > $75 \%,>50 \%$ chez $16(16,5 \%),<50 \%$ chez $17(17,5 \%)$ et aucun changement dans la fréquence des crises n'a été observé chez 44 patients $(45,5 \%)$. Trois patients ont interrompu le suivi. Chez $85 \%$ des patients qui ont eu une amélioration des crises, les résultats ont persisté plus d'un an. Conclusion: Le clobazam est sûr et efficace dans le traitement des encéphalopathies épileptiques de l'enfance.

Can. J. Neurol. Sci. 2006; 33: 209-213

The prevalence of epilepsy ranges from $0.5 \%$ to $1 \%$ in the general population. ${ }^{1}$ Seizures usually start in childhood and the majority of epileptic syndromes in this age group are benign. ${ }^{2}$ Nevertheless, some patients present with an unsatisfactory clinical course, with neurological deterioration, developmental delay and cognitive impairment. Most of these patients present with refractory epileptic syndromes and, as they do not respond effectively to monotherapy, they need adjunctive antiepileptic drugs (AEDs) for seizure control.

Clobazam is a 1.5-benzodiazepine with the imine group in the fourth and fifth position of the diazepine ring substituted by an amide. ${ }^{3}$ It has been used in the management of severe epilepsy for more than three decades. The antiepileptic effects of clobazam and its efficacy have been confirmed in several

From the Department of Neurology, State University of Campinas (Unicamp), São Paulo, Brazil.

ReCEIVEd July 15, 2005. ACCEPTED in FinAl FORM February 6, 2006. Reprint requests to: Marilisa M. Guerreiro, Department of Neurology, FCM/Unicamp, P.O Box 6111, 13083-970, Campinas, SP, Brazil 
studies. ${ }^{4-14}$ Clobazam is effective as add-on therapy in children with refractory epilepsies ${ }^{15,16}$ and can be used in encephalopathies, such as Lennox-Gastaut syndrome and severe myoclonic epilepsy of infancy. ${ }^{17-19}$

The effectiveness of clobazam has already been established by several studies. In addition, clobazam is much less expensive than the newer AEDs. However, clobazam is not widely used as a first-line therapy for epilepsy.

Epileptic encephalopathy is defined as a condition in which the epileptiform abnormalities themselves are believed to contribute to the progressive disturbance in cerebral function. ${ }^{20}$ The treatment of epileptic encephalopathy is one of the major challenges faced by pediatric neurologists. The purpose of this study was to evaluate the safety and efficacy of clobazam as addon therapy in children with epileptic encephalopathy.

\section{Methods}

This was a retrospective study, conducted at the pediatric epilepsy clinic of our university hospital. We evaluated patients who met all the inclusion criteria, from January 2004 to February 2005. Patients were interviewed by one of the authors according to a semi-structured questionnaire that included questions about the etiology of the epilepsy, previously used AEDs, seizure frequency and adverse events. We collected data from patients' routine visits and clinical files. The protocol and the informed consent were approved by the ethical committee of our university hospital.

Inclusion criteria were: age between six months and 18 years; diagnosis of epileptic encephalopathy according to the International League Against Epilepsy classification; ${ }^{20}$ previous failure of at least two monotherapies; use of clobazam as add-on therapy; signed informed consent by parents or legal guardian.

Exclusion criteria were: diagnosis of focal epilepsy; progressive metabolic disorders or brain tumors.

Clobazam was introduced as add-on therapy in patients with a previous failure of at least two monotherapies. The titration rate was determined by clinical response, but the interval of increasing the dosage was no less than one week. The dose escalation was in $5 \mathrm{mg}$ increments. The initial dose was $5 \mathrm{mg} /$ day at bedtime, and increased up to $60 \mathrm{mg} / \mathrm{day}$, twice a day. Clobazam was prescribed on the basis of a minimally effective dose up to the maximum tolerated dose. The dose was decreased or the drug stopped if the patient presented with an adverse event.

For analysis of the results, the patients were divided in four groups according to seizure control: a) seizure free; b) $>75 \%$ seizure reduction; c) $>50 \%$ seizure reduction, d) $<50 \%$ seizure reduction. The percentage of seizure control was established after the titration of clobazam, when the patient was taking the minimally effective/maximally tolerated dose.

We also evaluated the number of patients with improvement in seizure control, in whom a good response to clobazam lasted for more than one year.

We performed an analysis curve, according to Kaplan and Meier, for the continuation of the effect of clobazam during the 18 month period.
Table 1: Clinical and EEG characteristics of the 97 patients

$\begin{array}{cc}\begin{array}{c}\text { Age in years }(\mathbf{y}) \text { at } \\ \text { seizure onset }\end{array} & \text { No. of patients } \\ <1-3 \text { y } & 28 \\ 3-5 \text { y } & 20 \\ 5-7 \text { y } & 10 \\ 7-9 \text { y } & 9 \\ 9-11 \text { y } & 6 \\ 11-13 \text { y } & 12 \\ 13-17 \text { y } & 12\end{array}$

Seizures

Partial

Generalized

Partial and generalized

Indetermined

\section{Electroencephalogram}

Generalized epileptic activity $\quad 36$

Focal epileptic activity 25

Multifocal epileptic activity $\quad 15$

No epileptic activity $\quad 14$

Normal findings

\section{ReSUlts}

Ninety-seven patients were included in this study. Ages ranged from 1 to 17 -years-old (mean=9.9 years old). Thirty-nine of the patients were girls.

All patients presented with cognitive difficulties. In 14 patients this was the only finding at the neurological examination. Eighty-three patients had also at least one of the following findings: motor deficit $(n=19)$; hyperreflexia $(n=18)$; hypotonia $(n=18)$; hypertonia $(n=12)$; ataxia $(n=8)$; hyperactivity $(\mathrm{n}=6)$; nystagmus $(\mathrm{n}=5)$; and strabismus $(\mathrm{n}=2)$.

Table 1 shows the clinical, electroencephalographic (EEG) patterns, seizure classification and median age of seizure onset in all patients. Table 2 shows the neuroimaging (magnetic resonance imaging and/or computed tomography) findings.

Twenty-six patients had Lennox-Gastaut syndrome, seven had myoclonic astatic epilepsy, nine had West syndrome and, in 57 patients, the type of epileptic encephalopathy could not be determined. Two patients had a diagnosis of both LennoxGastaut and West syndrome. 
Table 2: Neuroimaging characteristics of the 97 patients

\begin{tabular}{lc} 
Neuroimaging & No. of patients \\
Cortical dysplasia & 14 \\
Cerebral atrophy & 4 \\
Microcephaly & 4 \\
Polymicrogyria & 4 \\
Tuberous sclerosis & 4 \\
Cerebellar atrophy & 3 \\
Hemimegalencephaly & 3 \\
Pachygyria & 2 \\
Hippocampal atrophy & 2 \\
Schizencephaly & 1 \\
Lissencephaly & 1 \\
Porencephalic cyst & 1 \\
Normal & 34 \\
\hline
\end{tabular}

All patients were using at least one AED when clobazam was introduced: 22 used carbamazepine (CBZ), 23 valproate (VPA), 15 phenytoin, 12 phenobarbital, 15 lamotrigine, 11 oxcarbazepine, 9 topiramate, 11 vigabatrin, 5 diazepam, 4 nitrazepam, 7 clonazepam and 3 divalproate.

At least three different AEDs (mean = 4) had been tried in each patient before the introduction of clobazam.

The clobazam dosage ranged from 5 to $60 \mathrm{mg} /$ day $($ mean $=$ $37.5 \mathrm{mg} /$ day), and patients took clobazam for a period ranging from one to 98 months (mean $=32.4$ months). Clobazam was discontinued when the maximum tolerated dose was reached without seizure improvement or due to adverse events.

Nine $(9.2 \%)$ patients were seizure-free after clobazam adjunctive therapy. Seizures improved $>75 \%$ in $11(11.3 \%)$ patients, $>50 \%$ in $16(16.5 \%)$ patients, $<50 \%$ in $17(17.5 \%)$ patients, and in $44(45.5 \%)$ patients there was no modification in the seizure frequency. Figure 1 shows the improvement in seizure control after clobazam adjunctive therapy. Three patients were lost to follow-up. Figure 2 shows the retention of clobazam over a period of 18 months.

The patients who were seizure-free were mainly those who previously had myoclonic seizures and they were administered clobazam at a dose of 25 to $50 \mathrm{mg} /$ day (mean $=35 \mathrm{mg} /$ day). Six of these patients, had their seizures completely controlled for more than one year.

Forty patients presented with adverse events, most of which were mild and transitory, and clobazam needed to be withdrawn in only 11 patients. Table 3 shows the number and type of adverse events presenting in these patients.

\section{Discussion}

In this study we evaluated the use of clobazam in the treatment of epileptic encephalopathies. The first - and possibly the major - challenge of this project was to classify the type of epileptic encephalopathy presenting in each patient. Although we used the well established criteria proposed by the International League Against Epilepsy, ${ }^{20}$ a specific type of epileptic encephalopathy - such as Lennox-Gastaut syndrome - could be determined in only $43 \%$ of the patients. This difficulty was due mostly to the high clinical heterogeneity of the seizures and unspecific electroencephalographic findings in many patients. This can be explained by the fact that the patient's age is one of the most import aspects in the determination of the epileptic syndrome because the type of epileptiform abnormality changes according to the degree of cerebral maturation. ${ }^{21}$ Older patients may present partial seizures and focal EEG abnormalities, but still meet the criteria for epileptic encephalopathy.

Our results showed that $9 \%$ of the patients became seizurefree and a significant seizure control $(>75 \%)$ occurred in $11 \%$. If we average the number of patients who improved $>50 \%$ or $<50 \%$ in seizure frequency, the chance of some improvement reaches $54 \%$. Considering the severity and the refractoriness of our patients, the seizure-free rate after the introduction of clobazam is quite impressive.

In other studies, between 26 and $61 \%$ of patients experienced an improvement in seizure control of more than $50 \%$ after addition of clobazam, which is in keeping with our findings $(37 \%)$. $^{22-29}$

In a prospective study of 115 children presenting with refractory epileptic syndromes, $18(16 \%)$ were seizure-free and $35(31 \%)$ had more than $90 \%$ reduction in the frequency of their seizures. ${ }^{29}$ The authors concluded that clobazam is effective in the treatment of various types of refractory epileptic syndromes in children and has a lower neurotoxicity level in comparison with other benzodiazepines.

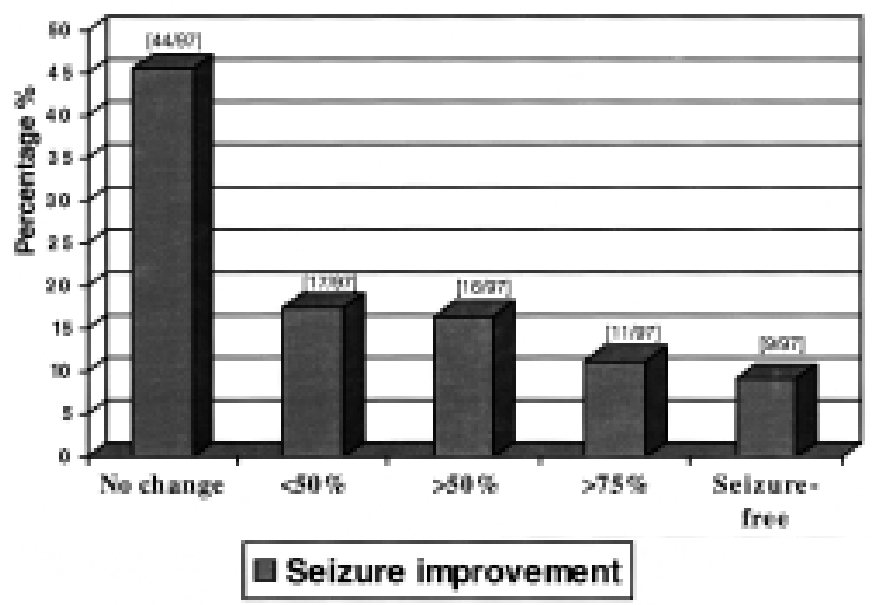

Figure 1: Number of patients with seizure improvement after clobazam adjunctive therapy. 


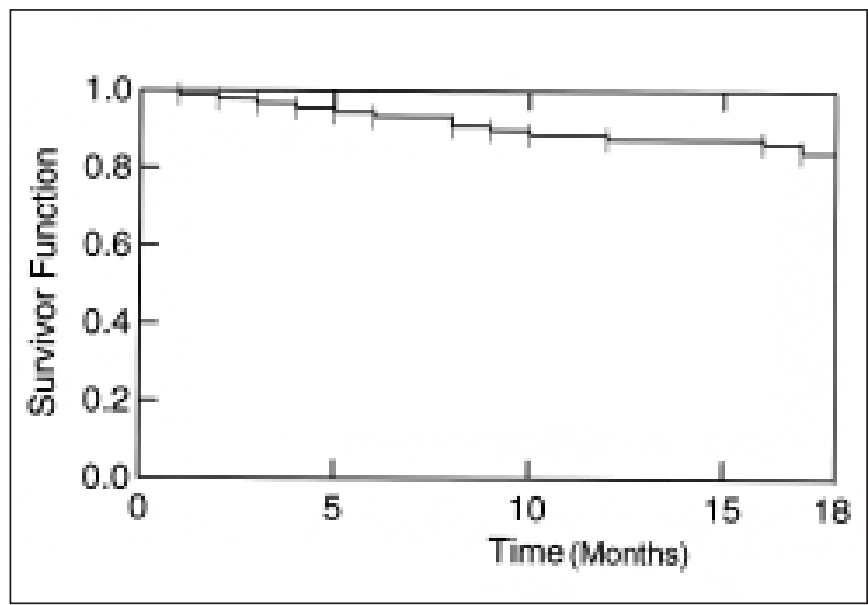

Figure 2: Kaplan-Meier analysis of endurance of effects of clobazam for 18 months. Time zero was considered the time at introduction of clobazam.

Our findings showed that clobazam is a safe drug as the adverse effects were mild and were tolerated by the patients. Although clobazam was withdrawn in 35 patients, in only 11 were adverse events the reason for withdrawal, showing that most patients tolerate mild or transitory symptoms if there is improvement in seizure control. Again, only in 11 of the 40 patients who presented with adverse events, did the drug have to be withdrawn. The main adverse event was somnolence (50\%). In the Canadian Clobazam Cooperative Group study, ${ }^{15}$ adverse effects (mostly somnolence) were present in $32 \%$ of patients and in $11 \%$ this was the reason for drug withdrawal.

Cognitive difficulties are always a concern in children taking AED. In this study, the patients already had a severe cognitive compromise due to the epileptic encephalopathy, precluding the assessment of new cognitive difficulties associated with the introduction of clobazam. We believe that higher doses of

Table 3: Adverse events occurring in $\mathbf{4 0}$ patients

\begin{tabular}{lc} 
Adverse event & No. of patients \\
Somnolence & 12 \\
Agitation & 9 \\
Apathy & 7 \\
Dizziness & 5 \\
Nausea/vomiting & 3 \\
Visual blurring & 2 \\
Bronchial hypersecretion & 1 \\
Cyanotic episodes & 1 \\
\hline
\end{tabular}

clobazam, as for most antiepileptic drug, may cause cognitive difficulties; however, only a different study design (including a comprehensive neuropsychological evaluation) would be able to address this issue in children with epileptic encephalopathy.

One of the major problems in the treatment of refractory epilepsy is tolerance to the AED. Tolerance to an AED is the loss of its antiepileptic effect after a previous period of improvement in seizure control. The tolerance to clobazam ranges from 7.578\%.5,11,15 The Canadian Study Group for Childhood Epilepsy ${ }^{4}$ found that tolerance developed in $7.5 \%$ of patients receiving clobazam, $4.2 \%$ with carbamazepine and $6.7 \%$ with phenytoin. We believe that the tolerance of clobazam has been overestimated. Our study showed that the retention of clobazam was $85 \%$ in a period of 12 months, which is in keeping with the other studies..$^{14,23,25}$

In conclusion, our data suggest that clobazam is equivalent to the so-called new AEDs as add-on therapy, with the benefit of good tolerability and low cost.

\section{REFERENCES}

1. Sander JW, Shorvon SD. Incidence and prevalence studies in epilepsy and their methodological problems: a review. J Neurol Neurosurg Psychiatry. 1987; 50(7): 829-39.

2. Camfield PR, Camfield CS. The prognosis of childhood epilepsy. Semin Pediatr Neurol. 1994; 1: 102-10.

3. Barzaghi F, Fournex R, Mantegazza P. Pharmacological and toxicological properties of clobazam (1-phenyl-5-methyl-8chloro-1,2,4,5-tetrahydro-2,4-diketo-3H-1,5- benzodiazepine), a new psychotherapeutic agent. Arzneimittelforschung. 1973; 23: 683-6.

4. Canadian Study Group for childhood epilepsy. Clobazam has equivalent efficacy to carbamazepine and phenitoin as monotherapy for childhood epilepsy. Epilepsia. 1998; 39: 952-9.

5. Schmidt D, Rohde M, Wolf P, Roeder-Wanner U. Clobazam for refractory focal epilepsy. A controlled trial. Arch Neurol. 1986; 43: 824-6.

6. Schmidt D. Clobazam for treatment of intractable epilepsy: a critical assessment. Epilepsia. 1994; 35 Suppl 5: S92-5.

7. Remy C. Clobazam in the treatment of epilepsy: a review of the literature. Epilepsia. 1994; 35 Suppl 5: S88-91.

8. Buchanan N. Clobazam in the treatment of epilepsy: prospective follow-up to 8 years. J Soc Med. 1993; 86: 378-80.

9. Singh A, Guberman AH, Boisvert D. Clobazam in long-term epilepsy treatment: sustained responders versus those developing tolerance. Epilepsia. 1995; 36: 789-803.

10. Reynolds EH, Heller AJ, Ring HA. Clobazam for epilepsy. Lancet. 1988; 2: 565.

11. Heller AJ, Ring HA, Reynolds EH. Factors relating to dramatic response to clobazam therapy in refractory epilepsy. Epilepsy Res. 1988; 2: 276-80.

12. Satishchandra P, Varadarajalu R, Rajaram P. Long-term use of clobazam in the management of intractable epilepsy: a prospective study. Neurology. 1998; 46: 284-7.

13. Shimizu H, KawasakiA J, Yuasa S, Tarao Y, Kumagai S, Kanemoto $\mathrm{K}$. Use of clobazam for the treatment of refractory complex partial seizures. Seizure. 2003; 12: 2820-6.

14. Montenegro MA, Ferreira CM, Cendes F, LI LM, Guerreiro CAM. Clobazam as add-on therapy for temporal lobe epilepsy and hippocampal sclerosis. Can J Neurol Sci. 2005; 32(1): 93-6.

15. Canadian Clobazam Cooperative Group. Clobazam in treatment of refractory epilepsy: the Canadian experience. A retrospective study. Epilepsia. 1991; 32: 407-16.

16. Dulac O, Figueroa D, Rey E, Arthuis M. Monotherapy with clobazam in epilepsies in children. Presse Méd. 1983; 12: 1067-9.

17. Dulac O. Epileptic encephalopathy. Epilepsia 2001; 42 Suppl 3: S23-6. 
18. Thanh TN, Chiron C, Dellatolas G, et al. Long-term efficacy and tolerance of stiripentaol in severe myoclonic epilepsy of infancy (Dravet's syndrome). Arch Pediatr. 2002; 9: 1120-7.

19. Schmidt D, Bourgeois B. A risk-benefit assessment of therapies for Lennox-Gastaut syndrome. Drug Safety. 2000; 22: 467-77.

20. Engel JJr, ILAE (International League Against Epilepsy). A proposed diagnostic scheme for people with epileptic seizures and with epilepsy: a report of the ILAE Task Force on Classification and Terminology. Epilepsia. 2001; 42(6): 796-803.

21. Avanzini G, Sancini G, Canafoglia L, Franceschetti S. Maturation of cortical physiological properties relevant to epileptogenesis. In: Abnormal Cortical Development and Epilepsy. Spreafico R, Avanzini G, Andermann F, editors. London: John-Libbey and Company; 1999: p. 63-75.

22. Montenegro MA, Cendes F, Noronha AL, Mory SB, Carvalho MI, Marques LH, et al. Efficacy of clobazam as add-on therapy in patients with refractory partial epilepsy. Epilepsia. 2001; 42: 539-42.
23. Barcs G, Halasz P. Effectiveness and tolerance of clobazam in temporal lobe epilepsy. Acta Neurol Scand. 1996; 93: 88-93.

24. Keene DL, Whiting S, Humphreys P. Clobazam as an add-on drug in the treatment of refractory epilepsy of childhood. Can J Neurol Sci. 1990; 17: 317-9.

25. Guberman A, Couture M, Baschuk K, Sherwin A. Add-on trial of clobazam in intractable adult epilepsy with plasma level correlations. Can J Neurol Sci. 1990; 17: 311-6.

26. Scott DF, Moffett A. The long-term effect of clobazam as adjunctive therapy in epilepsy. Acta Neurol Scand. 1988; 77: 498-502.

27. Allen JW, Oxley J, Robertson MM, Trimble MR, Richens A, Jawad SS. Clobazam as adjunctive treatment in refractory epilepsy. $\mathrm{Br}$ Med. 1983; 286: 1246-7.

28. Heller AJ, Ring HA, Reynolds EH. Clobazam for refractory epilepsy. Arch Neurol. 1987; 44: 578.

29. Munn R, Farrel K. Open study of clobazam in refractory epilepsy. Pediatr Neurol. 1993; 9(6): 465-9. 